\title{
Body composition and calcium metabolism in adult treated coeliac disease
}

\author{
S Bodé, C Hassager, E Gudmand-Høyer, C Christiansen
}

\begin{abstract}
Twenty two treated adult patients with coeliac disease (aged 20-70 years) were examined. Body composition was assessed from anthropometry and directly measured by dual photon absorptiometry. Bone mineral content was measured in the spine (dual photon absorptiometry) and at two forearm sites (single photon absorptiometry). Compared with age matched healthy subjects, treated coeliac patients had lower body mass index $(-5 \%, p<0.05)$ and lower directly measured total body fat mass $(-30 \%, p<0.001)$. They also had decreased bone mineral content $(-9$ to $-13 \%, p<0.01)$ in the spine and in the forearms. The serum concentrations of albumin, $\mathbf{D}$ vitamin binding protein, and iron were reduced $(-6$ to $-22 \%, p<0.01$ ), but otherwise blood and urine analyses were normal. We conclude that this group of treated adult coeliac patients had a reduced fat mass and bone mineral content compared with the general population.
\end{abstract}

Untreated patients with coeliac disease have often experienced considerable weight loss by the time of diagnosis ${ }^{1}$ and often have disturbances of calcium metabolism. ${ }^{12}$ It is well known that a gluten free diet may eliminate subjective symptoms and steatorrhoea, ${ }^{2}$ but whether such a diet completely restores normal body composition and calcium metabolism is not yet known. Collins $e t a l^{3}$ determined the nutritional state of 16 treated coeliac patients by anthropometric measurements and found that mild malnutrition frequently occurred. In a previous study ${ }^{4}$ we have shown that treated coeliac patients weighed less and had a correspondingly reduced body mass index compared with a reference population.

Few studies using modern techniques to evaluate the possible chronic bone lesions in treated coeliac disease have been published. Caraceni et $a l^{5}$ found reduced bone mineral density in 20 untreated coeliac patients, with no appreciable modification in treatment. Molteni et $a l^{6}$ found similar bone mineral density in 22 teenage patients treated from childhood and their controls, but significantly lower bone mineral density in 29 untreated adult coeliac patients compared with their controls.

We therefore investigated body composition and calcium metabolism in a group of adult coeliac patients on a gluten free diet.

\section{Methods}

PATIENTS

Twenty two adult patients with treated coeliac disease participated in the study: 15 women and seven men, median age 42 (range 20-70) years. They all had had a small intestinal biopsy consistent with the diagnosis, followed by an extensive clinical, and in 18 patients, histological response to a gluten free diet. Eight (36\%) of the patients were diagnosed in childhood and treated continuously from that time. A further nine (41\%) had experienced symptoms consistent with coeliac disease in childhood. Before the diagnosis was made, symptoms had been present for a median of seven (range $0 \cdot 5-35$ ) years. The 14 patients who were diagnosed as adults had, by the time of diagnosis, a median weight loss of 8.5 (range $0-27 \cdot 5$ ) $\mathrm{kg}$, and their weight gain after dietary treatment was started was (median) 9.75 (range 0-20) kg. By the time of the investigation the patients had been treated for a median of 3.6 (range 1-24) years. None of the patients had been treated with oestrogens, steroids, or anticonvulsant drugs. All patients took a multivitamin tablet daily, containing the recommended dose of vitamin $\mathrm{D}$. All were examined once by the methods listed below.

\section{RECORDING OF SYMPTOMS}

On a visual analogue scale, a $10.0 \mathrm{~cm}$ unmarked horizontal line, the patients recorded the severity of the following symptoms before (retrospectively) and after dietary treatment: aphthous ulcerations, constipation, nausea, joint pains, bone pains, abdominal pains, mental complaints, borborygmus, feeling of inadequacy, abdominal distension, lassitude, and diarrhoea.

In the same way the patients evaluated the severity of the illness, compliance with the diet, and the effect of the diet.

\section{ANTHROPOMETRIC MEASUREMENTS}

The body mass index as weight $/ \mathrm{height}^{2}\left(\mathrm{~kg} / \mathrm{m}^{2}\right)$ was calculated. The skinfold thickness at the following sites was measured by a mechanical caliper: biceps, triceps, subcapsular and suprailiac, and from this body fat mass and lean body mass were calculated. ${ }^{7}$ The arm muscle circumference (AMC) was calculated as $\mathrm{AMC}=$ midarm circumference $-0.314 \times$ triceps skinfold thickness.

\section{BONE MASS MEASUREMENTS AND BODY} COMPOSITION

Bone mineral content in the forearm was measured by single photon absorptiometry (Bone Mineral Analyzer 1100, Nuclear Data, USA). ${ }^{8}$ The first scan was obtained where the space between the ulna and radius is $8 \mathrm{~mm}$. The mean of six scans $4 \mathrm{~mm}$ apart in the proximal direction was expressed as proximal bone mineral 
content, whereas the mean of four scans $2 \mathrm{~mm}$ apart distal to the starting point was distal bone mineral content. The estimated content of trabecular bone is $13 \%$ at the proximal site and $55 \%$ at the distal site. Bone mineral density of the lumbar spine was measured by dual photon absorptiometry, using a ${ }^{153} \mathrm{Gd}$-source (DP3 Scanner, Lunar Radiation, USA). ${ }^{9}$ Forty scan lines $4 \mathrm{~mm}$ apart were obtained, and the bone mineral content and area were measured for vertebrae L2-L4. Bone mineral density was calculated as bone mineral content/area of interest. Total body bone mineral, lean body mass, and body fat mass, were also measured by dual photon absorptiometry. ${ }^{10}$ During one measurement of the total body, which takes 90 minutes in a normal adult, the subject lies supine
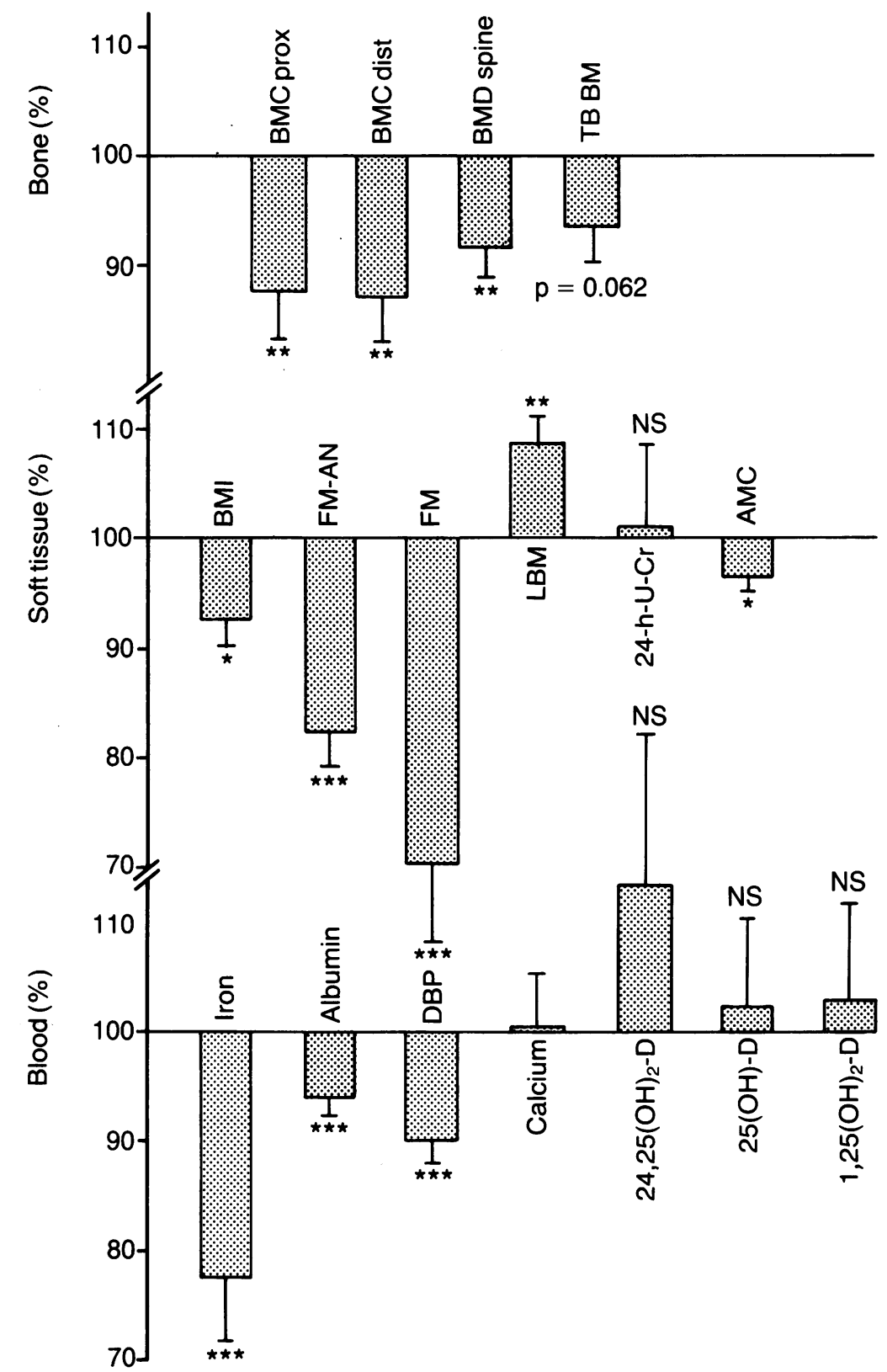

Results are expressed as percentage of mean $=100 \%$ of age and sex matched normal values (mean (SEM)). BMC prox and BMC dist=bone mineral content proximally and distally in the forearm. $B M D$ spine = bone mineral density in spine. $T B B M=$ total body bone mass. $B M I=$ body mass index. $F M-A N$ and $F M=$ body fat mass assessed from anthropometric measurements (percentage of the total body weight) and total body scan, respectively. $L B M=$ lean body mass. $24-h-U-C r=24$ hour urinary excretion of creatinine.

$A M C=$ arm muscle circumference. $D B P=$ vitamin $D$ binding protein. Calcium $=$ values corrected for serum albumin. $D=$ vitamin $D .{ }^{\star}=p<0.05, \star \star=p<0.01, \star \star \star=p<0.001$. $N S=$ not significant. with the source $\left({ }^{153} \mathrm{Gd}\right)$ moving below and the detector $(\mathrm{NaI})$ above in a rectilinear pattern.

\section{BLOOD ANALYSIS}

Blood samples were taken after an overnight fast. Bone Gla protein ( $\gamma$-carboxy-glutamic acid), 25hydroxyvitamin $\mathrm{D}$, and 24,25 -hydroxyvitamin $\mathrm{D}$ were measured by radioimmunoassay and 1,25-hydroxyvitamin D by a protein binding assay. The $\mathrm{D}$ vitamin binding protein was measured by rocket immunoelectrophoresis. Gliadin antibodies (IgA and IgG) were detected by a DIG-Elisa technique. The following analyses were carried out by routine methods: albumin, creatinine, protein, calcium, phosphate, alkaline phosphatase, cholesterol, high density lipoprotein, very low density lipoprotein, low density lipoprotein, triglycerides, haemoglobin, mean red cell volume, mean corpuscular haemoglobin, iron, transferrin, vitamin B-12 and folic acid concentrations and aminotransferase activities.

\section{URINE ANALYSIS}

Urinary hydroxyproline was measured by spectrophotometry. Urinary creatinine, sodium, calcium, and phosphate concentrations were measured by routine methods. Both fasting concentrations corrected for creatinine and 24 hour excretion were measured for all parameters.

\section{STATISTICS}

Due to the dependence of most of the measured parameters on age and sex, we expressed all results as a percentage of age and sex matched normal mean values. Differences from normal values were tested by Student's $t$ test for unpaired data. When considering results before and after treatment, the $t$ test for paired data was used. For regression analysis parametric statistics were used. Fisher's exact test was used to determine whether there was an association between bone mineral content and the presence of symptoms in childhood. Differences between means were considered to be significant at $\mathrm{p}<0.05$.

\section{Results}

Most symptoms were appreciably less severe after treatment. The exceptions were constipation, nausea, and bone and joint pain, which were present in only few patients. These symptoms were unaffected by the dietary treatment.

\section{BONE MASS MEASUREMENTS}

The results of the bone mass measurements appear at the top of the Figure. Bone mineral content was lower $(-7$ to $-13 \%)$ than normal at all measuring sites (proximal $-12 \%$, distal $-13 \%$, and bone mineral density spine $-9 \%$; six, six, and three patients, respectively, had values below thenormal range; $p<0.01$ ), although this was not significant for the total body bone mineral measurement $(-7 \%$; one patient had a value below the normal range; $p=0.06)$. The reduction in bone mineral content seemed 
uniform throughout the body in each patient, as there was agreement between the following parameters (in percentage of normal mean values): proximal and distal bone mineral content $(\mathrm{r}=0.964, \mathrm{p}<0.00001)$, bone mineral density spine and distal bone mineral content $(r=0.668$, $\mathrm{p}<0.01$ ), and total body bone mineral and distal mineral content $(\mathrm{r}=0.709), \mathrm{p}<0.001)$.

\section{BODY COMPOSITION MEASUREMENTS}

The middle of the Figure shows the body composition measurements. Compared with a Danish reference population," this group of patients had a reduced body mass index $(-5 \%$, all with the normal range; $p<0 \cdot 05)$. The patients had considerably reduced body fat mass $(\mathrm{p}<0.001)$, both when assessed anthropometrically $(-18 \%$; all within the normal range) and when measured directly $(-30 \%$; six patients had values below the normal range). The two measurements (in percentage of normal mean values) were in agreement $(\mathrm{r}=0.76, \mathrm{p}<0.001)$. Lean body mass, assessed from the total body scan, was increased $(+9 \%$, five patients had values above the normal range; $\mathrm{p}<0.01$ ), while the 24 hour urinary excretion of creatinine was normal, and the arm muscle circumference was slightly reduced $(-4 \%$; three patients had values below the normal range; $p<0.05$ ).

BLOOD ANALYSIS

Serum concentrations of albumin $(-6 \%), \mathrm{D}$ vitamin binding protein $(-10 \%)$, and iron $(-22 \%)$ were all lower than expected $(p=0.001)$. Bone Gla protein tended to be increased $(+43 \%$, $\mathrm{p}=0.09)$ because five patients $(23 \%)$ had values above the normal range, while the remaining results were normal. All the vitamin D metabolite and calcium concentrations (corrected for serum albumin) were within the normal range (Figure, bottom). The gliadin antibody titres were normal in all patients. The remaining blood analyses were normal.

URINE ANALYSIS

The fasting concentrations of hydroxyproline were raised $(+24 \%, p=0.053)$, while the 24 hour excretion of calcium was reduced $(-12 \%, \mathrm{p}=$ $0.094)$. The remaining urine analyses were normal.

\section{OTHER RELATIONS}

Bone mineral content (in percentage of normal mean values) was not associated with the duration $(\mathrm{r}=0.12)$ or severity $(\mathrm{r}=0.06)$ of symptoms before the diagnosis was made, or with the duration of treatment $(r=0.24)$ or compliance with the diet $(r=0 \cdot 12$, not significant). Patients who had been diagnosed, or who had experienced symptoms consistent with coeliac disease in childhood, did not have significantly increased abnormal bone mineral content compared with the rest of the patients $(p=0.19$ and $p=0.08$ respectively, Fisher's test). There was no association between the severity of bone pain after treatment and bone mineral content on bone Gla protein $(r=-0 \cdot 09$ and $r=-0 \cdot 13$ respectively, not significant).

\section{Discussion}

This group of patients with coeliac disease had been diagnosed and treated for at least one year before this investigation. They all responded well to dietary treatment, assessed from the normal results of the blood analysis, and from the fact that the patients reported only minor complaints by the time of the investigation. Only the sensitive blood analysis for malabsorption, albumin, and iron was affected. Despite this, the body fat mass was found to be reduced in these patients. This would be expected if the patients were still malnourished despite the diet. It might also be the case that the patients, having received frequent and comprehensive dietary information, ate a more healthy diet and therefore were less inclined to be overweight compared with the general population. Our three measurements for lean body mass gave slightly contradictory results, but the patients probably had normal muscle mass. Others have reported that patients with coeliac disease being treated by diet tend to be lean. ${ }^{3}$

Patients with untreated coeliac disease may have vitamin $\mathrm{D}$ deficiency ${ }^{12}$ and pronounced osteomalacia. ${ }^{212-14}$ In some cases osteomalacia is the most pronounced feature. ${ }^{15}$ Although the risk of osteomalacia may be reduced nowadays as the diagnosis usually is made at an earlier stage, the question is whether bone mineralisation is totally restored by dietary treatment. The present data suggest that this may not be so. Despite normal biochemical estimates of calcium metabolism, our subjects still had decreased bone mineral content compared with healthy subjects. A few other studies have addressed this question. Molteni et $a l^{6}$ found significantly reduced bone mineral density in treated adult coeliac patients compared with control subjects, with no correlation with the severity of the clinical history or the biochemical data of intestinal malabsorption. In contrast to this, their teenage patients with coeliac disease who had been treated from childhood had normal bone density. In another study Caraceni et $a l^{5}$ found reduced bone density in 20 adult coeliac patients compared with a sex and age matched control population, both before and after treatment, and no significant modification of bone mass was seen after treatment. Furthermore, it has been shown that coeliac patients can have osteomalacia without accompanying steatorrhoea. ${ }^{1617}$ In the present study the reduction in bone mineral content was not caused by a concurrent vitamin $\mathrm{D}$ deficiency, since we found normal serum concentrations of vitamin D metabolites, calcium, and phosphate, and normal urinary excretion of calcium and phosphate.

Some studies have shown a correlation between a reduced weight or body mass index and a reduced bone mineral content. ${ }^{18-20}$ Our patients tended to weigh less (not significant), and they had a significantly reduced body mass index because they tended to be taller than the reference population. We did not correct our bone mineral values for this because it would have resulted in 
only minor changes which would not have affected the conclusions of this study. Furthermore, the fact that our patients tended to be taller (not significant) than the reference population would influence the total bone mineral and mineral density of the spine in the opposite direction.

The reduction in bone mineral content found might be a consequence of previous vitamin $\mathrm{D}$ deficiency resulting in bone damage that took place before the diagnosis had been made. Or it might be the result of osteoporosis caused by calcium malabsorption and secondary hyperparathyroidism, malnutrition, or menstrual irregularities. To differentiate between osteomalacia and osteoporosis as the cause of the bone lesions, a bone biopsy is required. Although the patients had had proper treatment, their bones were not totally restored. This emphasises the importance of diagnosing the disease as early as possible so that treatment can be started and further bone damage prevented.

The reason we were unable to show a relation between the reduced bone mineral content and the duration or severity of the symptoms or the duration of treatment is probably due to the small sample of patients.

The consequences of the reduced bone mineral content is uncertain. The patients may have an increased risk of bone fractures. On the basis of this study we cannot recommend any treatment to cure the condition.

1 Green PA, Wollaeger EE. The clinical behavior of sprue in the United States. Gastroenterology 1960; 38: 399-418.

2 Cooke WT, Holmes GKT. Coeliac disease. Chapters 6, 7 Edinburgh: Churchill Livingstone, 1984

3 Collins BJ, Bell PM, Thomsen JM, Fee DB, Wilson EA, Love AHG. Dietary history and nutritional state in treated coeliac patients. $f R$ Soc Med 1986; 79: 206-9.
4 Bodé S, Bachmann E, Gudman-Høyer E, Jensen G. Stature of adult coeliac patients: No evidence for decreased attained height. Eur f Clin Nutr 1991; 45: 145-9.

5 Caraceni MP, Molteni N, Bardetella MT, Ortolani S, Nogara A, Bianchi PA. Bone and mineral metabolism in adult celiac A, Bianchi PA. Bone and mineral metabolism

6 Molteni N, Caraceni MP, Bardella MT, Ortolani S, Gandolini GG, Bianchi P. Bone mineral density in adult celiac patients and the effect of gluten-free diet from childhood. Am $\mathcal{F}$ Gastroenterol 1990; 1: 51-3.

7 Durnin JVGA, Womersley J. Body fat assessed from total body density and its estimation from skinfold thickness measurements on 481 men and women aged from 16 to 72 years. BrF Nutr 1974; 32: 77-97.

8 Christiansen C, Rødbro P, Jensen $\mathrm{H}$. Bone mineral conten in the forearm measured by photon absorptiometry. Principles and reliability. Scand $\mathcal{f}$ Clin Lab Invest 1975; 35: ciples and $323-30$.

9 Nilas L, Hassager C, Christiansen C. Long-term precision of dual photon absorptiometry in the lumbar spine in clinical dual photon absorptiometry in the lumb
settings. Bone Miner 1988; 3: 305-15.

10 Gotfredsen A, Jensen J, Borg J, Christiansen C. Measurements of lean body mass and total body fat using dual photon absorptiometry. Metabolism 1986; 35: 88-93.

11 Jensen G. Epidemiology of chest pain and angina pectoris with special reference to treatment needs. Acta Med Scand 1984 (suppl 682): 1-120.

12 Melvin KEW, Hepner GW, Bordier P, Neale G, Joplin GF. Calcium metabolism and bone pathology in adult coeliac disease. OF Med 1970; 153: 83-113.

13 Smith $R$. Disorders of the skeleton. In: Weatherall DR Ledingham JGG, Warrell DA, eds. Oxford textbook of Ledingham JGG, Warrell DA, eds. Oxford textbook of
medicine. vol 2. Oxford: Oxford University Press, 1983; medicine.

14 Thalayasingam B. Coeliac disease as a cause of osteomalacia and rickets in the Asian immigrant population. $B M \mathcal{F} 1985$; 290: 1146-7.

15 Hajiar ET, Vincenti F, Salti IS. Gluten-induced enteropathy Arch Intern Med 1974; 134: 565-6.

16 Hepner GW, Jowsey J, Gordon S, Roginsky M, Young JF. Osteomalacia and celiac disease. Am $\mathcal{f}$ Med 1978; 65: 1015 20.

17 Moss AS, Waterhouse C, Terry R. Gluten-sensitive enteropathy with osteomalacia but without steatorrhea. $N \mathrm{Englf}$ Med 1965; 272: 825 .

18 Ribot C, Tremollieres F, Pouilles J-M, Bonneu M, Germain F Louvet J-P. Obesity and post-menopausal bone loss: the influence of obesity on vertebral density and bone turnover in post-menopausal women. Bone $1988 ; 8: 327-31$.

19 Pocock NA, Eisman JA, Yeates MG, Sambrook PN, Eberl S Physical fitness is a major determinant of femoral neck and lumbar spine bone mineral density. $\mathcal{F}$ Clin Invest 1986; 78 618-21.

20 Sowers MFR, Wallace RB, Lemke JH. Correlates of midradius bone density among post-menopausal women: community study. Am $\mathcal{F}$ Clin Nutr 1985; 41: 1045-53. 